\title{
Paisagem urbana contemporânea e Geografia das redes na escola: uma contribuição ao estágio-docência em Geografia
}

\begin{abstract}
RESUMO: 0 presente trabalho analisa a formação docente no âmbito do estágio surpervisionado durante a licenciatura em Geografia compreendendo que a concepção de profissional crítico-reflexivo se constitui pela discussão do papel da ciência e do conhecimento na formação geral dos cidadãos. É na universidade que se constroem as relações dialéticas e dialógicas entre ensino-pesquisa, teoria-prática, fomento basilar para a(s) leitura(s) da paisagem urbana contemporânea em que se situam as escolas campo de estágio.
\end{abstract}

\section{Contemporary urban landscape and Geography of networks in school: a contribution to the stage-teaching in Geography}

\footnotetext{
ABSTRACT: This work analyzes the teacher training under the internship during the licentiate in geography including the design of critical-reflective professional is by discussing the role of science and knowledge in general training of citizens. Is at the university who build dialectical relations between dialogical and teaching-research, theory-practice, promoting basic (s) reading (s) of the contemporary urban landscape in which they are located schools internship field.
}

Marlene Macario Oliveira* Aldo Gomes Leandro**

*Professora Ms. em Geografia pela Universidade Federal do Rio Grande do Norte. Coordena o Curso de Licenciatura em Geografia da Universidade Estadual Vale do Acarau e Universidade Aberta Vida em Campina Grande - PB

${ }^{* *}$ Professor Substituto no Departamento de História e Geografia da Universidade Estadual da Paraíba e Doutorando em Geografia pela Universidade Federal de Pernambuco.

Palavras-chave: Formação de Professores em Geografia; Estagio Supervisionado.; Paisagem urbana contemporânea e Ensino-Pesquisa.

Key-words: Teacher training in geography; Supervised Stage. Contemporary urban landscape. Education-Search. 


\section{Introduzindo a questão de estudo}

Esse texto tem por objetivo refletir a formação de professores durante 0 estágio supervisionado no âmbito da licenciatura em Geografia estabelecendo relações entre a paisagem urbana contemporânea em que se situam as escolas campo de estágio, imbricada no espaço educativo da escola, pois entende-se que essa manifesta o contexto socioespacial em que os educandos estão inseridos quer seja nos conteúdos e currículos, quer seja pela complexa teia tecida por conceitos e práticas, preceitos e dogmas, discursos e interdições discursivas (NOVENA, 2008).

Em sua construção buscamos respostas às seguintes questões: a) De que forma 0 contexto da formação docente durante o estágio supervisionado em Geografia influencia na formação de docentes críticos, criativos e reflexivos capazes de fomentar uma leitura múltipla e dinâmica da paisagem urbana contemporânea no cotidiano escolar? b) As representações sociais de estágio-docência em Geografia pelos alunos durante o estágio supervisionado contribuem para a leitura múltipla e dinâmica da paisagem urbana contemporânea em que se situam a rede de escolas da cidade?

A análise se situa no âmbito global das políticas publicas de formação docente adotadas no país, na medida em que fomentam uma organização curricular que prevê dois conjuntos de estudo, congregando, de um lado, as disciplinas técnico-científicas e, de outro, as disciplinas didático (psico) pedagógicas típico "modelo 3+1" (PONTUSCHKA; PAGANELLI; CACETE, 2007) reforçando uma relação entre a universidade e a escola pautada na distância e/ou estranhamento entre o estagiário, a escola e a cidade. Essa perspectiva é objeto das atuais reformas educacionais e é bastante discutida no âmbito dos debates acadêmicos e das entidades científicas e profissionais requerendo aprofundamento da reflexão acerca da natureza e dos objetivos dos cursos de formação desses profissionais.

Reconhece-se que as novas abordagens teórico-metodológicas das ciências sociais e humanas trazem alguns avanços no que diz respeito ao desenvolvimento da capacidade reflexiva, crítica e criativa do professor no contexto da licenciatura e da atuação na escola. No entanto, nos cursos de licenciatura em Geografia durante o estágio supervisionado tem-se constatado uma frequente desvinculação teórico-metodológica da diversidade de concepções e métodos dessa ciência sobre 0 ensino quando considerada a relação que se poderia construir com a paisagem urbana em que está inserida a escola.

Reconhecer o potencial elucidativo da morfologia do mundo visível em que se situam as escolas, em que pese à existência das coisas e objetos, como função, estrutura e processo; por outro lado, o modo como são objetivadas as construções mentais, afetivas e ideológicas da docência em Geografia favorece o desenvolvimento do pensamento espacial. Esses elementos interferem na formatação do ambiente vivido, na atuação profissional e nos discursos que daí emergem (MACIEL, 2004, p. 03).

O estágio supervisionado tem um papel fundamental na formação dos futuros professores se considerada a importância do ensino-pesquisa durante a atuação discente na escola. As atividades solicitadas tanto de observação e participação, como de regência, possibilitam ao aluno, em formação, compreender e atuar no espaço fazendo uma relação entre os conteúdos acadêmicos apreendidos e o espaço vivido.

Ao adquirir informações, conhecimentos e habilidades, ou seja, interpretações objetivas e subjetivas do lugar-mundo que se fomentará possibilidades para lidar com os complexos 
desafios da construção do conhecimento na escola. Destarte, são nessas relações estabelecidas que tomamos consciência de nós e dos demais em relação a nós. É certamente pela linguagem, seus sistemas cognitivos e a rede de interações estabelecidas o conditio sine qua non à manutenção dos vários status quo vigentes que configuram a noção do eu-outronatureza.

Reconhecer essa conjectura no contexto específico dessa atividade de formação, em especial, o papel que desempenha na formação de valores na e para a cidade nas suas mais variadas manifestações poderá contribuir para uma leitura mais apropriada da paisagem urbana contemporânea pela atuação docência, favorecendo ao estímulo sensorial das ações que efetivam no solo.

O acionamento destes códigos no contexto das interações socioculturais vigentes por meio do desenvolvimento de categorias e procedimentos de análise associados a contextos e domínios específicos, a universos simbólicos distintos possibilitam que os indivíduos se reconheçam enquanto sujeitos que permanentemente se reconstroem a partir das relações que mantêm entre si, na coletividade e na natureza. Afinal, a cidade, a educação, o conhecimento são construídos por homens que não se esgotam numa dimensão biológica e ou funcional, mas compõem suas histórias através da existência em sociedade.

Assim, urge que se fomente, durante o estágio supervisionado na licenciatura em Geografia, condições materiais para uma educação do contexto urbano contemporâneo considerando a dinâmica cultural dos alunos em formação para a identificação profissional e identitária do exercício do magistério na Geografia escolar.

\section{A docência em Geografia: Questões norteadoras}

A Geografia na Educação Básica, assim como as demais disciplinas escolares, passa por sérias críticas. Essas decorrem de suas origens vinculadas aos interesses de consolidação do Estado Nacional e do capitalismo do século XXI (PEREIRA e ANDRADE, 1999). No Brasil representou uma posição secundária na ordem das prioridades educacionais, percurso que acabou por comprometer a formação do professor de Geografia quanto à construção da identidade profissional, da prática cotidiana nos espaços escolares e de sua vinculação com os conteúdos locais e com a vida dos indivíduos.

Nesse sentido a escola passou a reproduzir um conjunto de informações caóticas, unilaterais, aparentemente revestidas de um conteúdo de ensino, negando a territorialidade dos lugares construídos por homens concretos, históricos e contraditórios, constituindo a expressão da violência simbólica (LEANDRO et al., 2009a).

As décadas 1970 e 1980 com a chamada "Geografia Crítica" não superaram tais práticas tidas como tradicionais. Situação que se agravou com as mudanças na relação espaço-tempo vivenciadas pela sociedade a partir dos processos de globalização e fragmentação, assim como com as políticas educacionais decorrentes a exemplo de um conjunto de leis, programas e projetos voltados para a operacionalização ou "equidade" via educação. De caráter assistencialista, clientelista e patrimonialista essas práticas espaciais ampliaram a imensa fratura entre os direitos educacionais e a cidadania efetiva, acenando para a ausência de parâmetros públicos de reconhecimento dos direitos sociais, des(re)construindo identidades e jogando os seres humanos numa aleatória, desigual e violenta luta pela sobrevivência.

Geografia Ensino \& Pesquisa, v. 15, n.3, p. 207216, maio./ago. 2011

Oliveira,M. M.; Leandro A. G. 
Consideramos que a escola do século XXI é espaço concreto, repleto de vivências, conflitos, contradições, constituídos no movimento, dialético e dialógico, da sociedade. Esse para ser democrático precisa ser conquistado por grupos diferenciados da sociedade na cidade, lugar, região e mundo. Nesse sentido, a universidade tem papel preponderante, embora muitas ainda conduzam as suas ações por um projeto pedagógico baseado numa racionalidade técnica modelo adotado pelas antigas Faculdades de Filosofia dos anos 1930 e que se encontra defasado diante da realidade do magistério. O conjunto de conhecimentos técnicos e pedagógicos desvinculados da reflexão teórico-prática e dos contextos locais é um equivoco que se segue no processo de formação continuada (PIMENTA e LIMA, 2009).

Nas licenciaturas, a inadequação dos currículos é verificada pela desarticulação entre os componentes curriculares "específicos" da Geografia e os componentes de cunho didáticopedagógico como didática, metodologia do ensino, prática de ensino e estágio supervisionado, limitando a perspectiva de autonomia do professor diante da complexidade da prática pedagógica atual, caracterizada por incertezas e conflitos de valores. Para a superação desse modelo, é preciso uma reflexão constante do processo de formação dos profissionais no contato com a realidade escolar, quando considerado o espaço da escola como lugar de pesquisa, de formação de saberes e práticas e não somente de aplicação de técnicas (CAVALCANTI, 2006).

Alguns princípios orientam para a construção desse sentido como a articulação entre teoria-prática-ensino e a pesquisa, bem como a atenção às diferentes capacidades e habilidades para o trabalho profissional. É possivel identificar alguns desses princípios na legislação atual, apesar dos contratempos e desvios em sua aplicação. No âmbito federal destacam-se as Diretrizes Curriculares Nacionais para a Formação de Professores da Educação Básica (Resolução CNE/CP, 2002), as Diretrizes Curriculares para o Curso de Graduação de Geografia (Resolução CES 14/2002) e a Lei $n^{0} 11.788$, de 25 de Setembro de 2008. Esses princípios apontam para algumas mudanças nas propostas de estágio nas licenciaturas e na relação teoria-prática, colocando, dentre outras questões, a necessidade de ampliação do número de horas/aula dos componentes curriculares envolvidos. É importante frisar que a ampliação da carga horária não representa isoladamente um fator de avanço se estiver desconectada das propostas de articulação entre conteúdos, saberes e práticas entre a universidade e a educação básica.

A concepção de estágio como "disciplina acadêmica" contribui para o distanciamento entre a universidade e a educação básica e não acompanha as mudanças da sociedade contemporânea, dificultando parcerias mais efetivas, reforçando a inserção do estagiário no cotidiano escolar como um mero observador e reprodutor que cumpre exigências formais do currículo. Esse "desconhecimento" da dinâmica contemporânea e cotidiana do espaço escolar é um entrave à escola cidadã/educadora (GADOTTI; ROMÃO, 2004).

Cumpre observar a importância da pesquisa no trato com a complexa trama de relações vivenciadas no espaço escolar na/da cidade como os desafios anteriormente apresentados. A formação do professor-pesquisador estudioso dessas questões no cotidiano escolar é uma necessidade que se coloca às licenciaturas brasileiras hoje (LEANDRO; OLIVEIRA; FIGUEIREDO GILL, 2009b).

\footnotetext{
Paisagem urbana contemporânea e Geografia das redes na escola: uma contribuição ao estágio-docência em Geografia 


\section{Para uma leitura da paisagem urbana contemporânea: algumas reflexões}

O modelo da tradicional postura da Geografia escolar quando agregado às práticas docentes no âmbito da licenciatura contribui para um futuro exercício do magistério e de seu arcabouço cultural viúvo de concepções teórico-metodológicas dessa ciência no contexto das interações sócio-culturais na escola e na cidade. Ao assumir essa perspectiva se promove a baixa teorização e reflexividade dos conteúdos acadêmicos e de suas explicações se considerada a dimensão do ser estar no mundo desvelando a necessidade de uma discussão ética, estética e política da sociedade que a organiza. Um exercício filosófico e ontológico da Geografia no âmbito da licenciatura poderá torná-la um todo inteligivel para 0 aluno em formação, sobremaneira, se parte de construções espaciais do urbano, do rural, dos conflitos e das diferenças entre os grupos no planejamento do ensino.

Nessa perspectiva, a formação docente requer do professor uma sintonia com o contexto sociocultural de produção, circulação, consumo e de comunicação dos sujeitos na sociedade, a produção de seu conhecimento científico, sociopolítico e cultural na ordem econômica globallocal dado que esses transformam os territórios, o lugar, a paisagem e configura as relações sociais e de trabalho de diferentes grupos, sobretudo na realização do estágio-docência. No âmbito da formação docente, a apropriação do conhecimento, das técnicas de comunicação e de informação pelos sujeitos envolvidos se constitui em elemento basilar para a superação de tal modelo, incluindo o domínio dos recursos didáticos para fundamentar o exercício do magistério.

Essa teia complexa, comumente chamada de redes técnico-cientifico-informacionais (SANTOS, 2005), incide sobre as representações sociais de estágio-docência pelos alunos da licenciatura em Geografia pela(s) forma (s) como se apropriam de seu contexto socio-espacial de formação, suas formas de circulação, de comunicação, de informação e de apropriação dos bens e serviços públicos da universidade, da cidade e da escola.

Esses alunos, em sua maioria advindos de escolas públicas, ao entrarem na universidade apresentam conflitos de ordem social, política, econômica e cultural decorrente da segregação socioespacial e que, de certo modo, se manifesta na conduta mantida por esses quando relacionada aos fatores externos: condições socioeconômicas das famílias, ao grau de instruções dos pais, os escassos recursos públicos, a política educacional entre outros. Não é necessário listar os inúmeros problemas para perceber que essas questões atuam em conjunto e se articulam num eterno conflito aberto, configurando a formação docente durante a realização do estágio supervisionado.

Como não se pode analisar esse contexto de formação de forma independente da rede de significados em que se inscreve a perspectiva de seus participantes, pois esse é espelho que guia e orienta as suas interações humanas com o meio físico e antropossocial, recebendo a influência das estruturas sociais e educacionais vigentes questiona-se que significações são construídas? Seus conteúdos e metodologias favorecem a pesquisa do espaço vivido? No processo de formação favorecem a reflexão dos conteúdos materializados na paisagem urbana contemporânea do lugar como um texto carregado de símbolos e significados a ser lido e interpretado como documento social na escola? (COSGROVE \& JACKSON, 1987, p. 19 apud CORREAA \& ROSENDAHL, 2000). A formação docente e a Geografia ensinada, e apreendida contribui para 0 autoconhecimento subjetivo e interações dialética e dialógica reflexivas e transformadoras da vida cotidiana na escola e na cidade?

Reconhece-se que as representações sociais de formação docente decorrem das redes sociais em que esses sujeitos estão inseridos. Essas associadas às concepções de homem,

Geografia Ensino \& Pesquisa, v. 15, n.3, p. 207216, maio./ago. 2011

Oliveira,M. M.; Leandro A. G.

ISSN 2236- 4994 211 
mundo, sociedade, cultura, meio ambiente, favorecem a construção de uma leitura dinâmica e plural da paisagem urbana contemporânea. Assim, uma participação mais efetiva no estágiodocência incorre num investimento científico, filosófico, político e didático-pedagógico da ciência geográfica em face do capital cultural herdado pelos sujeitos da pesquisa (ALMEIDA, 2007).

Moscovici (1978, p. 26-28) já argumentava que as representações sociais consistem num conhecimento prático, do senso comum, ancorado no mundo da interação social, pensamento circunscrito na realidade que modela e remaneja o que é dado externamente no contexto dos valores, das noções e das regras, do qual os indivíduos são solidários.

0 autor considera que mesmo passando por transformações as representações sociais reproduzem, assimilam e difunde-se no meio social, convergindo algo individual para o social e vice-versa. Assim, as representações passam da vida de todos para a de cada um, do nível consciente ao inconsciente (MOSCOVICl apud JODELET, 2001, p. 62).

Assim, ao representar, o indivíduo prediz e antecipa os atos vinculando os dados da realidade aos seus sistemas de valores, de noções e práticas dos sujeitos, orientando a interação social e material, determinado os comportamentos e as práticas, possibilitando dominá-los e, por outro lado, viabilizando esses novos conhecimentos para que sejam denominados e incluídos em categorias de interpretação e reconhecimento de mundo, da história individual e coletiva (Idem, 1978).

As representações sociais que os indivíduos ou os grupos têm e utilizam para agir e para tomar posição é indispensável para a compreensão da dinâmica das interações sociais e para clarificar os determinantes das práticas sociais. 0 mundo se constitui de significados divididos e compartilhados. Compreender aquilo que se pensa e se comunica em suas múltiplas dimensões, contradições e paradoxos representam um caminho para se pensar à leitura que se tem e se pode ter de mundo (SPINK, 1993).

A Teoria das Representações Sociais diz sobre a forma de apropriação, produção, elaboração e construção do conhecimento, que se relaciona com o mundo, com as regras, os valores, símbolos e signos significativos para os sujeitos e para os grupos. Sua compreensão imbrica reflexão da dimensão histórico-cultural e essa pode ser respaldada pelos mediadores biofísicos e psicossocioculturais fundamentais no processo, mas considerando-os num movimento multidimensional para efetivação de uma gestão educacional cooperativa e comprometida com a qualidade da educação na cidade e no Brasil.

Assim, utilizar-se das representações sociais sobre a docência apreendidas na licenciatura em Geografia a partir das relações que se materializam no espaço urbano incorrem em implicações política(s) e educativa(s) tanto na universidade quanto na educação básica. Assim, urge que se fomente a leitura da paisagem urbana contemporânea durante 0 estágio supervisionado estabelecendo interconexões com a Geografia das Redes em que se situam as escolas da cidade para superação do caráter pragmático e funcionalista do arquétipo educacional, fruto de mecanismos perversos e ocultos na cidade. Esses são responsáveis pelas contradições socioespaciais e desigualdades na construção do conhecimento de estudantes pertencentes a diferentes grupos sociais quanto à apropriação do espaço.

A um investimento teórico-prático na qualidade dos futuros profissionais implica uma aproximação com o contexto sócio-espacial em que esses estejam inseridos durante a formação docente, das conexões que fazem sobre os seus aspectos objetivos e subjetivos, e isso pressupõe a análise da paisagem dado que essa está estreitamente vinculada a um sistema prévio de representações da relação entre 0 social, 0 cultural, 0 intelectual, 0 patrimonial e 0 cívico e constitui-se num sistema prévio de significações em relação tanto às práticas políticas

Paisagem urbana contemporânea e Geografia estágio-docência em Geografia 
estruturadas, como às intenções individuais como afirma Duncan (1990). 0 autor compara a paisagem a um texto, através do qual os seus leitores podem ou não legitimar o discurso dominante ${ }^{1} \mathrm{e}$ isso decorre das imagens que são construídas no contexto sócio, político, econômico e cultural, dos seus significados compartilhados que são comunicados, reproduzidos, experienciados e explorados.

Berque (1998), considera a paisagem como marca e matriz posto que ela evidencia a relação de determinada sociedade com a área em que habita e revela suas formas de percepção da natureza. A paisagem, como marca, pode ser representada de forma pormenorizada, seus caracteres podem ser descritos, enumerados e analisados. Esse conceito nos dá a idéia de movimento, transformação, ação das diversas formas de vida sobre 0 ambiente físico ou natural, considerado por Sauer (2000), como paisagem - matriz, que vai sendo moldada e resulta na paisagem cultural. Sob esse aspecto, é evidente a ideia de mutabilidade, de mudanças que ocorrem de acordo com o momento histórico e os valores políticos, culturais, econômicos que prevalecem para distintos grupos sociais.

A paisagem, herança do geógrafo americano Carl Sauer, da Escola de Berkeley, da Geografia Cultural da década de 20, do século XX, adquiriu na Geografia Humanística uma existência viva e plural resultante de uma leitura múltipla, dinâmica e polissêmica que constitui 0 tecido urbano, a trama sociopolítica tecida entre os indivíduos e os territórios configurando-se em conexões ambientais, sociais, culturais e identitárias relacionando-se com outros lugares num contexto plural, amplo e diverso. A paisagem é portadora de significados, expressa os valores, as crenças, os mitos e as utopias dos seres que as habitam, tendo, portanto, uma dimensão cultural. Assim, a paisagem entendida como um conceito-chave da geografia (CORREA \& ROSENDAHL, 1998, p. 08) passa a se constituir num caminho para se perceber simultaneamente o conjunto de elementos que estão interagindo na construção do espaço.

Sobre esse aspecto é possível ainda constatar que a sala de aula é considerada "espaço privilegiado" para a realização do estágio supervisionado e isso legitima uma perspectiva dicotomizada e reducionista, ou seja, simulacros da geografia na escola e da geografia da cidade reafirmando o seu "caráter de celas" (SOJA, 1993). Desse modo, o sujeito que habita a cidade se destitui da capacidade criadora e transformadora, assumindo apenas o perfil de consumidor de bens e serviços, desvinculando-se de seu papel político enquanto agente da produção do espaço, e da cidadania.

Ressaltamos que a relação entre a universidade, o estágio supervisionado e a escola pública, não pode desconsiderar a geografia das redes na cidade e sua influência sobre essas, com especial atenção às redes sociais em que se encontram os estagiários. As representações sociogeográficas que esses constroem do lugar definem a acessibilidade às escolas públicas campo de estágio, bem como as representações sociais sobre a prática docente reafirmando determinados mecanismos de segregação socioespacial (CAVALCANTI, 2008).

O sentido desse movimento está em olhar o homem como síntese, ao mesmo tempo psíquica, sociológica, econômica, histórica e demográfica do mundo que habita (MORIN, 1984). Possibilita a transparência constituitiva do ser, para tanto, precisamos pesquisá-la, meter-se nela, fluir com ela.

A propósito as redes em que se inserem os diferentes grupos sociais da universidade pública têm grande potencial de configurar a experiência do estágio-docência quer seja pelo acesso a circulação, quer pelas técnicas de informação e de comunicação. Essas delineiam o movimento presente nas paisagens da cidade e por sua capacidade virtual de criar condições
1 Discurso para Duncan (1990) é definido como uma estrutura social de inteligibilidade, na qual todas as práticas são comunicadas, negociadas ou desafiadas.
Geografia Ensino \& Pesquisa, v. 15, n.3, p. 207216, maio./ago. 2011

Oliveira,M. M.; Leandro A. G. 
sociais inéditas modificam a ordem econômica mundial transformando territórios (DIAS, 2000, p. 143), sobretudo, por estarmos "inseridos" num momento de grande complexidade no que diz respeito àqueles que produzem e controlam as redes em macro-escala.

Sobre essa dimensão Haesbaert (2002) considerando o caráter global das redes, afirma que as mesmas não têm capacidade de preencher todo o espaço, já que são formadas por fluxos e pontos fixos, ou seja, lacunas são deixadas para que outras formas de organização espacial, que não necessariamente as hegemônicas, se constituam. Para o autor, é necessário destacarmos o papel das redes que se configuram em uma escala de ação menor (local e regional). Raffestin (1993) expõe que a rede faz e desfaz as prisões do espaço, tornado território-rede: tanto liberta como aprisiona. Moreira (2004) nos apresenta a idéia de que, se encontrar em rede significa, analogamente, achar-se em um certo lugar em rede, parecendo que o lugar chega ao sinônimo de nó, ponto de acessibilidade na rede. Para se inserir numa rede deve-se estar "lugarizado", poderíamos dizer também, territorializado - em rede.

A não consideração desses elementos tem implicações diretas na formação do professor de geografia no que diz respeito à concepção de cidade e de ensino de geografia, reforçando a deseducação do espaço citadino, aumenta-se a distância entre a perspectiva de formação do cidadão crítico e atuante, transformador do seu cotidiano e dos conteúdos geográficos.

\section{Mais algumas palavras}

A pesquisa aponta que a principal dificuldade à formação de professores consiste na falta de domínio de questões fundamentais do conhecimento geográfico inerente as experiências sócio-espaciais de alunos em formação interrelacionadas ao contexto espacial em que se situam as escolas campo de estágio. Essa lacuna têm se demonstrado como a principal mantedora da posição de repetidores, de transmissores mecânicos de conteúdos na sala de aula. Sua superação poderá ocorrer durante o percurso da licenciatura em Geografia para contribuir a identificação profissional da docência na vida coletiva e pública, de seus exercícios formais e/ou jurídicos na luta pelo reconhecimento de suas práticas sociais e culturais.

A apreensão da paisagem urbana contemporânea inerente às redes de escola na cidade $e$ de sua interrelação ao contexto sócio-espacial do estágio supervisionado pelas representações sociais de estágio-docência de alunos em seus espaços, tempos, relações institucionais expressa as marcas da cultura e os universos simbólicos distintos, incluindo os selos da vivência e do afeto, pois aí se encontrariam os códigos, valores e símbolos caracterizando pertenças e referências, como também demandas e respostas efetivas e afetivas, hábitos e desejos afirma (MADEIRA 2005, p.462).

Assim, caberá ao estágio supervisionado em Geografia incentivar teorias, práticas, metodologias e significações políticas durante o estágio-regência, no ensino fundamental e médio, para que se possa interrelacionar os fatos e acontecimentos concretos que marcam 0 cotidiano desses discentes a partir dos eventos que caracterizam a paisagem urbana

Geografia Ensino \& Pesquisa, v. 15, n.3, p. 207216, set./dez. 2011

Paisagem urbana contemporânea e Geografia das redes na escola: uma contribuição ao estágio-docência em Geografia contemporânea das escolas campo de estágio para o reconhecimento da cultura da formação docente e a produção de seus territórios na universidade e de seus futuros exercícios nas escolas públicas.

A superação do descompasso existente na Geografia acadêmica e escolar, na divisão entre a Geografia que se propaga nos cursos de graduação e a Geografia que se pratica nas salas de 
aula da Educação Básica supõe uma gestão científica, política e educativa favorável à circulação, produção e distribuição dos bens e serviços públicos na cidade, podendo inferir a produção do conhecimento democrático na cidade com fomento a construção de um saber científico mais coadunado com os problemas que interferem na sociedade.

De nada adianta participarmos da escola se essa instituição não fornece os elementos indispensáveis para que os alunos possam compreender o meio em que vivem correlacionar os fatos e os fenômenos que interferem nas estruturas sócio-econômico-culturais, e construir bases para forjar a transformação. Isso pressupõe a reflexão coletiva da vida e da humanidade a partir do compartilhamento de seus sentidos e de seus significados, sobretudo para o desenvolvimento do pensamento espacial numa perspectiva de reforço a valores de sociabilidade, co-presença, solidariedade, respeito às diferenças e fortalece atitudes de responsabilidade social.

\section{Referências}

ALMEIDA, Ana Maria F. A noção de capital cultural é útil para se pensar o Brasil? In: PAIXÃO, Lea Pinheiro; ZAGO, Nadir (Org.). Sociologia da educação: pesquisa e realidade. Petrópolis, RJ: Vozes, 2007, p. 44-59.

BERQUE, Augustin. Paisagem - marca, paisagem - matriz: elementos da problemática para uma Geografia Cultural. In: CORREAA, R. L.; ROSENDAHL, Z.(Org.) . Paisagem, Tempo e Cultura. Rio de Janeiro, EdUERJ, 1998, p. 84-89.

CAVALCANTI, L. S. A geografia escolar e a cidade. Ensaios sobre 0 ensino de geografia para a vida urbana cotidiana. Campinas: São Paulo: Papirus, 2008.

CAVALCANTI, Lana de S. (Org.). Formação de professores: concepções e práticas em Geografia. Goiânia: Editora Vieira, 2006.

CORREA, R. L., ROSENDAHL, Z. (orgs.). Geografia Cultural: um século. Rio de Janeiro: EdUERJ, 2000.

CORREA, R.L., ROSENDAHL, Z. (orgs.). Paisagem, tempo e cultura. Rio de Janeiro: EdUERJ, 1998.

DIAS, L. C. Redes: emergência e organização. In: CASTRO, I. E.; GOMES, P. C. C.; CORRÊA, R. L.(orgs.). Geografia: conceitos e temas. $2^{\mathrm{a}}$ Ed. Rio de Janeiro: Bertrand Brasil, 2000, p. 141-162.

DUNCAN, J. S. The city as text: the politics of landscape interpretation in the Kandyan Kingdom. Cambridge: Cambridge University Press, 1990.

GADOTTI, Moacir; ROMÃO, José E. (Orgs.). Autonomia da escola: princípios e propostas. São Paulo: Instituto Paulo Freire, 2004.

HAESBAERT, Rogério. Territórios Alternativos. Niterói: EdUFF, São Paulo: Contexto, 2002.

JODELET, Denise. Representações sociais: um domínio em expansão. In: JODELET, D. As representações sociais. Rio de Janeiro: Ed. UERJ, 2001, p. 17- 44.

LEANDRO, A. G. et al. A prática de ensino e o estágio supervisionado na UEPB: reflexões a partir da formação docente. In: $10^{\circ}$ Encontro Nacional de Prática de Ensino em Geografia. Rio Grande do Sul: Porto Alegre, 2009a.

LEANDRO, A. G.; OLIVEIRA, M. M.; FIGUEIREDO GILL, M. P. C. A escola e o estágio supervisionado: diálogos e trocas de experiências. In: II Fórum Internacional de Pedagogia. Paraíba: Campina Grande, $2009 \mathrm{~b}$.

MACIEL, C. A. A. Morfologia da paisagem e imaginário geográfico: uma encruzilhada onto-gnoseológica. Geographia. Universidade Federal Fluminense. ano III - $n^{0} 6$ - jul-dez 2001 - publicação on-line em dezembro

Geografia Ensino \& Pesquisa, v. 15, n.3, p. 207216, maio./ago. 2011

Oliveira,M. M.; Leandro A. G. 
de 2004. Disponível em: http://www.uff.br/geographia/rev_06/caio6.pdf

MADEIRA, Margot Campos. Representações sociais e processo discursivo. In: MOREIRA, A. S. P. (Org.). Perspectivas teórico-metodológicas em representações sociais. João Pessoa, UFPB/Editora Universitária, 2005, p. 459-469.

MOREIRA, Ruy. O círculo e a espiral: para a crítica da geografia que se ensina. Niterói, Edições AGB Niterói, 2004.

MORIN, Edgar. Idéias Contemporâneas - Entrevistas do Le Monde. São Paulo: Ática, 1984.

MOSCOVICI, S. A representação social: um conceito perdido. In: MOSCOVICI, Serge. A representação social da psicanálise. Rio de Janeiro: Zahar, 1978, p. 41-81.

NOVENA, N. P. Pesquisando as narrativas da sexualidade na organização escolar: formulação do problema e adequação dos procedimentos metodológicos na pesquisa qualitativa. In; FARIAS, M. S. B; WEBER, S. (orgs). Pesquisas qualitativas nas ciências sociais e na educação proposta de análise do discurso. João Pessoa: Editora Universitária da UFPB, 2008, p. 167-190.

PONTUSCHKA, N. N.; PAGANELLI, T. I.; CACETE, N. H. Para ensinar e aprender geografia. São Paulo: Cortez, 2007.

PEREIRA, Raquel \& ANDRADE, Raquel M. F. de. Da geografia que se ensina à gênese da geografia moderna. Florianópolis: UFSC, 1999.

PIMENTA, Selma G.; LIMA, M. do S. L. Estágio e docência. São Paulo: Cortez, 2009.

RAFFESTIN, Claude. Por uma geografia do poder. São Paulo: Ática, 1993.

SANTOS, Milton. A urbanização brasileira. São Paulo: EDUSP, 2005.

SAUER, Carl O. A morfologia da paisagem. In: CORREAA, R. L.; ROSENDAHL, Z. Paisagem, tempo e cultura. Rio de Janeiro: EdUERJ, 1998, p. 75-83.

SOJA, E. W. Geografias pós-modernas: a reafirmação do espaço na teoria social crítica. Rio de Janeiro, Jorge Zahar Ed., 1993.

SPINK, M. J. Desvendando as teorias implícitas: uma metodologia de análise em representações sociais. In: Textos em Representações Sociais. GUARESCHI, P. A; JOVCHELOVITCH, S. (Orgs.). 8. ed.. Rio de Janeiro: Vozes, 2003, p.117-145.

Geografia Ensino \& Pesquisa, v. 15, n.3, p. 207-

216, set./dez. 2011

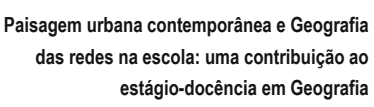

